\title{
Study of the Performance of Natural Fiber Reinforced Composites for Wind Turbine Blade Applications
}

\author{
Temesgen Batu ${ }^{1,2}$, Hirpa G. Lemu ${ }^{3 *}$, Belete Sirhabizuh ${ }^{1}$ \\ 1 Dept. of Mechanical Engineering, Addis Ababa Science and Technology University, Addis Ababa, Ethiopia \\ 2 School of Mechanical and Industrial Engineering, Wollo University, Ethiopia \\ 3 Faculty of Science and Technology, University of Stavanger, N-4036 Stavanger, Norway \\ * Corresponding author's e-mail: Hirpa.g.lemu@uis.no
}

\begin{abstract}
The availability of some form of energy is essential for the human survival and social development. However, the way energy has been generated within the last century has brought forward the quest for the generation of energy without polluting the environment, which is nowadays considered to be the greatest global challenge. The materials used for wind turbine blades can be classified under this challenge of polluting the environment. One of the materials expected to reduce this problem is natural fiber reinforced composite (FRC). Thus, the focus of this paper was to evaluate the potential of different natural FRC materials for small wind turbine blade application. Eleven different natural fibers reinforced composite in epoxy resin were studied. A modified Halphin-Tsai semi-empirical model was used to compute the physical properties of the composites, since it has a good agreement with the experimental results. Stress, deformation, and weight of wind turbine blade under different loadings were analyzed aimed to search for a fiber type that may extend the life span of the blade. Finally, flap wise and edge wise, the longitudinal and torsional natural frequencies were computed numerically by using the finite element method in the Qblade software (QFEM) under different mode types and the effects were analysed. Upon comparing the results with a common composite material for wind turbine blade (E-glass/epoxy), it was observed that the selected natural fiber composites have equivalent and better mechanical performance. The environmental friendliness of natural fibers, i.e. biodegradability, constitutes their advantage as materials of wind turbine blades.
\end{abstract}

Keywords: Natural fiber, reinforced composite, wind turbine blade, Qblade

\section{INTRODUCTION}

Energy is largely considered as the driver of industrial developments and almost everything in our daily life has a direct relation with the availability of some form of energy. Due to the progressively increasing concern for the environmental deterioration caused by fossil fuel based energy sources, renewable sources are nowadays highly focused upon. Among the available renewables, the wind energy is nowadays considered as the most reliable and cleanest of all renewable energy sources. As a result, a major part of future energy supply is expected to depend on the energy obtained from the wind. In order to improve the energy conversion efficiency of wind energy converters and guarantee their economic feasibility, further research and development may focus on two potential areas, namely (1) innovative design solutions of the wind turbine blades and (2) the designs that reduce the mechanical losses. Both issues demand an in-depth understanding of the flow characteristics of the wind passing the turbine blades. Thus, the design of turbine blades including the shape, airfoil form, material type, number of blades, structure and processing technology of the blades [1-3] are the key performance parameters of the design optimization tasks of wind energy converters. In a wind turbine system, the most critical component is the wind turbine blade, because it has direct relation with the mechanical efficiency of energy conversion 
and the manufacturing cost of the blades is approximately one fifth of the total cost for all components [4].

The generation of energy without polluting the environment is the greatest challenge of the twenty-first century. Proper material selection for wind turbine blades has a dual impact on the environment. On one hand, the efficient and cost effective energy conversion from the wind reduces the portion of fossil fuels in our energy consumption, and on the other hand, the use of materials that are biodegradable will positively contribute to the environment. Nowadays, many wind turbine blade manufacturers use glass fiber reinforced and carbon fiber reinforced composites. These materials are attractive for turbine blades because of their high strength, high elastic modulus and increased fatigue life. Those composites possess adequate structural properties but they are non-biodegradable, health hazardous, non-recyclable, expensive, give abrasion to the machine, and consume high amounts of energy in their production process. These limitations are the attributes of synthetic fibres that stimulate researchers to develop alternative materials for wind turbine rotor blades.

Natural fibre-reinforced composites can be used as a viable alternative material in order to meet the demands of renewability and recyclability, as well as reduce the cost of wind turbines. Different researchers have proposed natural fiber reinforced composites for wind turbine blade design $[5,6]$. various natural fibers such as bamboo, sisal, curanua, ramie, etc. can be considered for the purpose, but their mechanical properties are not yet sufficiently studied, though many natural fibers have good mechanical properties, are easy to process and biodegradable.

Among others, more work is needed on the mechanical strength, vibration and fatigue analysis of natural fiber reinforced composites for wind turbine blade application. As the used material type is responsible for the application specific strength, different researchers focused on the stress analysis of synthetic composite wind turbine blades. Deshmukh and Shekhawat [7] studied the performance of four different composite materials and concluded that carbon epoxy is one of the best material for wind turbine blade under the specified conditions. Yeh et al. [8] solved comprehensive stress, maximum stress, thermal stress and deformation of glass fiber reinforced plastic turbine blade using a finite element method and summarized stress analysis on the blade.

The vibration frequencies and mode shapes are also the focus of research in wind turbine blades. The physical properties of materials affect the vibrations of any structure. Thus, a good wind turbine blade design should attempt to minimize vibrations by avoiding resonance. As a result, the reduction of vibration is a good measure for a successful design in the blade structure [9]. If the material property of any structure is changed, the natural frequency of the structure is altered as well. Therefore, studying the effect of materials on vibration analysis is a mandatory part of design where vibrations can appear. Knowing the geometric shape and the material properties of the blade, the natural frequencies can be estimated using the finite element analysis.

The aim of this study was to investigate different natural fiber reinforced composite for a wind turbine blade using the finite element method. Stress, deformation and modal behavior of the blade were analyzed for different natural fiber reinforced composite materials. The Qblade software, which is a dedicated tool for airfoil analysis, was used to conduct the modal analysis of some selected reinforced composite materials.

\section{MATERIALS AND METHODS}

\section{Design of material properties of natural fiber reinforced composite}

The elastic properties of a composite can be predicted by the micromechanics models based on the properties of the individual constituent materials of the composite and their geometrical characteristics. The most useful approach is the use of semi-empirical models, which are widely employed to predict the elastic modulus of composites because the model results agree well with the experimental results. The other method used to estimate the modulus of elasticity of composites is the Halphin and Tsai method. The Halpin-Tsai equation can give the modulus of elasticity in the transverse direction, but it has to be modified for randomly oriented fiber reinforced composites.

Recently, a modified Halphin and Tsai method was recommended to predict the modulus (E) for natural fibers based composites [10] by further improving different parameters for the model 
through adjustment, to make specific composites using data from experiments. This modified relation is given as:

$$
\mathrm{E}=\mathrm{A}\left(\sin ^{-1} \alpha V_{f}^{\beta}\right)\left(\frac{3}{8} E_{1}+\frac{5}{8} E_{2}\right)
$$

where $A, \alpha$ and $\beta$ are model constants to simulate composite modulus for $\mathrm{A}=1, \alpha=3 \pi / 2$ and $\beta=11 / 16$ and $V_{f}$ is fiber volume fraction. $E_{1}$ and $E_{2}$ are composite moduli in the lateral and transverse directions, respectively, based on the Halpin-Tsai equation using $\xi=2$ (an estimated parameter referred to as reinforcing efficiency) for the transverse direction.

$E_{1}$ and $E_{2}$ are obtained from the HalpinTsai equation by using equation (2) - (4).

$$
\begin{gathered}
E_{1}=E_{f} \times V_{f}+E_{m} \times V_{m} \\
E_{2}=E_{m}\left(\frac{1+\xi \eta V_{f}}{1-\eta V_{f}}\right) \\
\eta=\frac{E_{f}-E_{m}}{E_{f}+\xi E_{m}}
\end{gathered}
$$

where: $E_{F}$ and $E_{M}$ are fiber and matrix modulus, respectively, and

$V_{f}$ and $V_{m}$ are the corresponding fiber and matrix volume fractions. The density of the composite is also computed using the rule of mixtures as in equation (5).

$$
\rho_{c}=\rho_{f} V_{f}+\rho_{m} V_{m}
$$

where: $\rho_{f}$ and $\rho_{m}$ are density of fiber and matrix respectively.

The properties of each fiber, i.e. the values of density, Young's modulus and tensile strength, are obtained from experimentally published materials [5, 11-13], and these values for the selected natural fibers are reported in Table 1. Epoxy resin, the Young's modulus of which is $3.4 \mathrm{GPa}$ $[14,15]$, was used as matrix for all fibers. As there are large variations of modulus of elastisticity and density of fibers reported in the published materials, the maximum value of the properties obtained from the literature was considered for all of them.

Using equation (1) to (5) and the properties listed in Table 1, the modulus of elasticity and density were used for the finite element analysis and computation. Table 2 shows the results of different mechanical properties (modulus of elasticity and density) of the selected natural fiber reinforced composites obtained from a modified Halphin-Tsai method.

As can be observed from the computed results in Table 2, some epoxy reinforced natural fiber composites have similar or higher Young's modulus than glass fiber. The composites reinforced with Jute, hemp, flax and pineapple fiber have the higher Young's modulus value than the other natural fiber reinforced composites.

Table 1. Mechanical properties of fibers

\begin{tabular}{|l|c|c|c|c|c|c|c|}
\hline \multicolumn{1}{|c|}{ Fiber name } & Banana & Abaca & Flax & Sisal & Pineapple & Kenaf & Hemp \\
\hline Density of fiber $\rho_{\mathrm{f}}\left(\mathrm{g} / \mathrm{cm}^{3}\right)$ & 1.5 & 1.5 & 1.5 & 1.45 & 1.53 & 1.4 & 1.48 \\
\hline Young's modulus $(\mathrm{GPa})$ & 17.85 & 20 & 80 & 38 & 84.5 & 53 & 70 \\
\hline Tensile strength $(\mathrm{MPa})$ & 600 & 980 & 1500 & 700 & 1627 & 930 & 900 \\
\hline \multicolumn{1}{|c|}{ Fiber name } & & Bamboo & Jute & Curanua & Ramie & E-glass \\
\hline Density of fiber $\rho_{\mathrm{f}}\left(\mathrm{g} / \mathrm{cm}^{3}\right)$ & & 1.18 & 1.46 & 1.4 & 1.5 & 2.5 \\
\hline Young's modulus $(\mathrm{GPa})$ & & 32 & 30 & 96 & 128 & 70 \\
\hline Tensile strength $(\mathrm{MPa})$ & 800 & 800 & 803 & 938 & 3500 \\
\hline
\end{tabular}

Table 2. Mechanical properties of different composite materials

\begin{tabular}{|l|c|c|c|c|c|c|}
\hline \multicolumn{1}{|c|}{ Properties } & $\begin{array}{c}\text { Banana } \\
\text { lepoxy }\end{array}$ & $\begin{array}{c}\text { Abaca/ } \\
\text { epoxy }\end{array}$ & $\begin{array}{c}\text { Flax/ } \\
\text { epoxy }\end{array}$ & $\begin{array}{c}\text { Sisal/ } \\
\text { epoxy }\end{array}$ & $\begin{array}{c}\text { Pineapple/ } \\
\text { epoxy }\end{array}$ & $\begin{array}{c}\text { Kenaf/ } \\
\text { epoxy }\end{array}$ \\
\hline Young's modulus $(\mathrm{GPa})$ & 10.228 & 10.993 & 27.393 & 16.563 & 28.485 & 20.62 \\
\hline Density $\left(\mathrm{kg} / \mathrm{m}^{3}\right)$ & 1365 & 1365 & 1365 & 1337.5 & 1381.5 & 1310 \\
\hline Properties & $\begin{array}{c}\text { Hemp/ } \\
\text { epoxy }\end{array}$ & $\begin{array}{c}\text { Bamboo/ } \\
\text { epoxy }\end{array}$ & $\begin{array}{c}\text { Jute/ } \\
\text { epoxy }\end{array}$ & $\begin{array}{c}\text { Curaua/ } \\
\text { epoxy }\end{array}$ & $\begin{array}{c}\text { Ramie/ } \\
\text { epoxy }\end{array}$ & $\begin{array}{c}\text { E-glass/ } \\
\text { epoxy }\end{array}$ \\
\hline Young's modulus $(\mathrm{GPa})$ & 24.935 & 14.826 & 26.905 & 31.247 & 38.779 & 24.935 \\
\hline Density $\left(\mathrm{kg} / \mathrm{m}^{3}\right)$ & 1354 & 1189 & 1343 & 1310 & 1365 & 1915 \\
\hline
\end{tabular}




\section{Load acting on the blade}

The blades are exposed to the loads from three different sources, namely (1) wind load, (2) gravity and (3) centrifugal load. As centrifugal forces are relatively low [16], this load type is not considered in further analysis. The wind loads mainly induce both flap wise and edgewise bending of the blade, and are dynamic by their nature. The basic types of wind loads that play a crucial role in the structural strength and stiffness of the blade are the aerodynamic loads. The aerodynamic load acting on the blades can be divided into tangential and axial force components. Figure 1 shows a wind turbine of three blades in its plane of rotation and the force components acting at each section of the blades.

The tangential $\left(\mathrm{F}_{\mathrm{T}}\right)$ and axial forces $\left(\mathrm{F}_{\mathrm{N}}\right)$ are identified by resolving the lift and drag force components. The tangential force provides torque for the power generation, while the axial component force imposes structural loading on the support and tower of the turbine. The blade force is computed at each section of the blade. Thus, the tangential and normal force computed at each section along the blade are expressed as in equation (6).

$$
\begin{aligned}
& F_{N}=L \cos \phi+D \sin \phi \\
& F_{T}=L \sin \phi-D \cos \phi
\end{aligned}
$$

where: $\phi$ and $\alpha, L, D$ and $F_{R}$ are flow angle, angle of attack, lift force, drag force and resultant force, respectively.

\section{Blade model and FE analysis}

Qblade is an open source tool recently developed to assist the design and simulation of wind turbines $[17,18]$. It uses the blade element momentum (BEM) theory to simulate the horizontal axis turbines to compute the stresses on the blades and simulate their aerodynamic performance, also in modal analysis. The software is intended to create a single tool consisting of the necessary functionalities for the aerodynamic design and simulation. Thus, it can serve as an independent tool with no need for data importing from other sources and converting them to other forms or data processing steps. To enable this, Qblade is equipped with the following key functionalities or modules that are accessible from its graphical user interface [19]:

- Airfoil design and analysis

- Polar extrapolation of drag and lift forces

- Design and optimization of airfoil blades

- Turbine definition and simulation.

The blade selected for this paper is one of the research wind turbines used by the Department of Aerospace and Mechanical Engineering at the University Notre Dame, Indiana [19]. For modeling the blade geometry, such blade parameters as the chord length and twist angle are needed. These and other relevant rotor geometry specifications are listed in Table 3.

Using the rotor geometry of the blade, it has been modeled as shown in Figure 2 by using the Qblade software (QFEM). Then, the model was imported to QFEM and the mechanical properties defined. The aerodynamic load (consisting both tangential and normal forces) was computed for $\mathrm{V}_{\text {rated }}$ wind speed of $11.6 \mathrm{~m} / \mathrm{s}$. The load was applied to the blade model and the stresses, total deformation and weight of the blade were calculated.

In the model, both shell and internal structure (i.e. hollow with spar) were filled with the composite material (cross-section in Figure 3(a)). Furthermore, a unidirectional fiber composite was assumed because the fibers are randomly oriented or aligned in the matrix material, as illustrated in Figure 3(b).

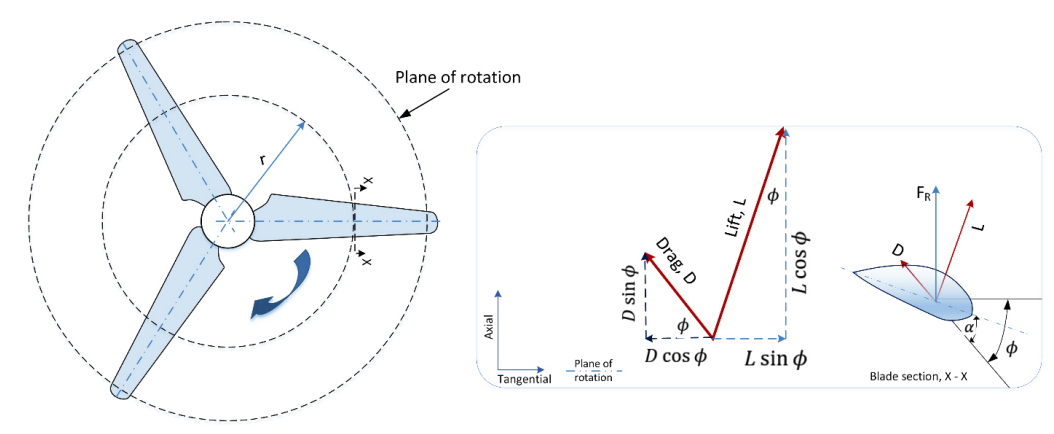

Fig. 1 Resolved components of blade forces 
Table 3. Specification of University of Notre Dame in Notre Dame, Indiana wind turbine [19]

\begin{tabular}{|l|c|}
\hline \multicolumn{1}{|c|}{ Parameter } & Value $(\mathrm{s})$ \\
\hline $\mathrm{C}_{\mathrm{L}}(\alpha)$ & $0.327+0.1059 \alpha-0.0013 \alpha^{2}$ \\
\hline $\mathrm{C}_{\mathrm{D}}(\alpha)$ & $0.006458-0.000272 \alpha+$ \\
$0.000219 \alpha^{2}-0.0000003 \alpha^{3}$
\end{tabular}

\section{RESULTS AND DISCUSSION}

\section{Comparison of equivalent stress, directional deformation and weight of the blade}

The results of the loading simulation are plotted in Graph View as shown in Figure 4. For the case shown, the result indicates that the maximum obtained von Mises stress is $405.77 \mathrm{MPa}$ and the tip deflected is $0.758 \mathrm{~m}$ along $\mathrm{x}$ direction and $0.894 \mathrm{~m}$ along $\mathrm{z}$ direction for Banana/epoxy properties.
The von Mises stress results for 11 different natural fibers and that of a commonly used glass fiber are listed in Table 4 (stress plots are not given for page limitations). As can be observed from the tabulated stress values, the selected natural fibers have different stress levels and hence perform differently. Compared with glass fiber, almost all of them fit the strength requirement in the area.

For a good and safe design of turbine blades, the deformation and stress level should satisfy the expected values for the specific application and low weight is needed. The fact that the von Mises stress analysis results of glass/epoxy is at equivalent stress level with that of the natural fiber/epoxy blade implies that these natural fiber composites can replace the glass fiber composite applications with additional environmental benefits, because natural fibers are biodegradable.

The finite element analysis results also show that the material with the least deflection is Ramie/epoxy, while least von-Misses stress was registered for Abaca/epoxy and Banana/epoxy. In terms of weight, a bamboo/Epoxy blade can

\begin{tabular}{|l|c|c|}
\hline \multicolumn{3}{|l|}{ Blade geometry } \\
\hline Radius(m) & Chord (mm) & Blade twist $(\varphi)$ \\
\hline 1.196 & 467.62 & 14.39 \\
\hline 1.404 & 421.45 & 11.89 \\
\hline 1.613 & 382.21 & 9.92 \\
\hline 1.822 & 349.07 & 8.34 \\
\hline 2.031 & 323.59 & 7.05 \\
\hline 2.239 & 303.19 & 5.98 \\
\hline 2.448 & 287.05 & 5.08 \\
\hline 2.657 & 274.53 & 4.31 \\
\hline 2.865 & 259.42 & 3.64 \\
\hline 3.074 & 249.51 & 3.07 \\
\hline 3.283 & 239.74 & 2.56 \\
\hline 3.492 & 230.16 & 2.11 \\
\hline 3.7 & 220.04 & 1.71 \\
\hline 3.909 & 211.77 & 1.34 \\
\hline 4.118 & 204.56 & 1.03 \\
\hline 4.327 & 200.88 & 0.73 \\
\hline 4.535 & 196.84 & 0.47 \\
\hline 4.744 & 192.37 & 0.22 \\
\hline 4.953 & 188.02 & 0 \\
\hline
\end{tabular}

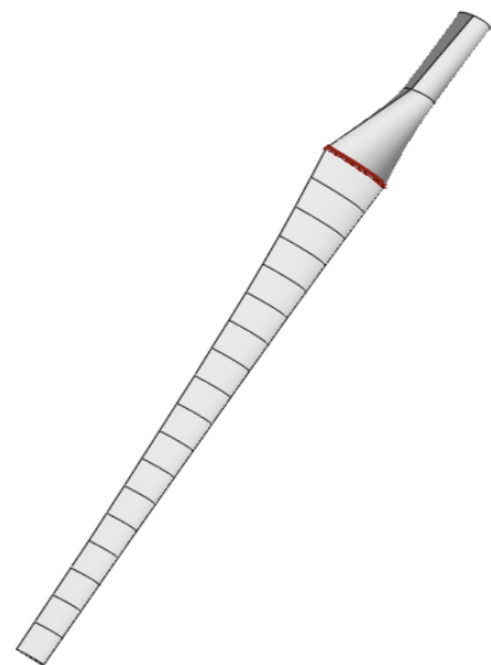

Fig. 2 Blade model in Qblade software
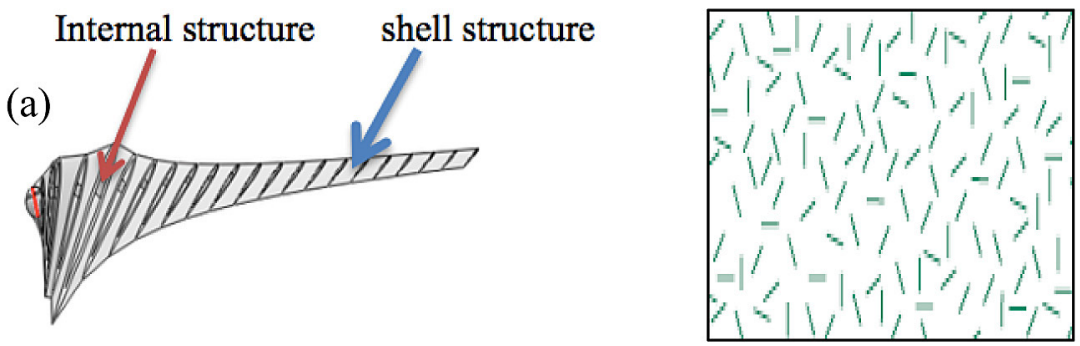

(b)

Fig. 3 (a) blade cross-section and (b) illustration of random orientation of fibers in the matrix 


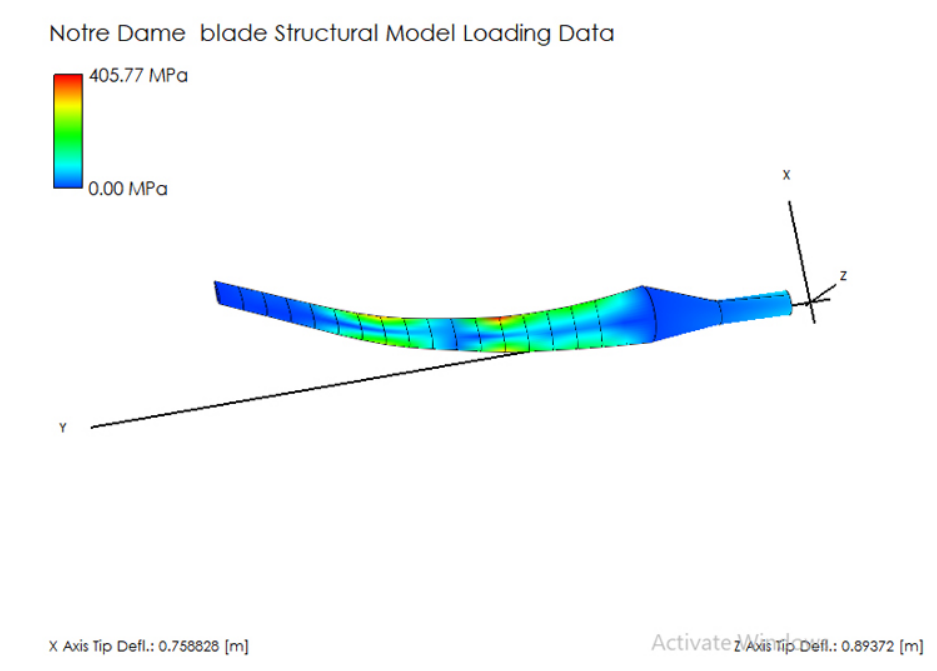

Fig. 4 Equivalent (von-Mises) and deformation of the blade

be a favored natural fiber reinforced composite for the wind turbine blade application because a low weight blade allows rotation of the turbine with small amount of wind speed. Thus, the number of rotations of the blade increases, which has direct relation with power extracted, i.e. the output power is improved.

The advantage of low weight (density) blade is that the wind blade easily overcomes friction and begins to rotate within a low cut in wind speed. A wind turbine design that reduces the cut-in wind speed through a proper design of the blades will be characterized by a significant performance improvement [20]. Thus, one of the ways to reduce the cut-in speed is reducing the weight of the turbine blade. As can be seen from Table 4, compared with E-glass/epoxy, the weight of natural fiber reinforced composite wind turbine blade is lower by $27.89 \%$ to $38 \%$ for the selected natural fibers. Natural fiber reinforced composites are favorable materials for the wind turbine blade design in terms of weight reduction, and show similar stress and deformation levels with E-glass blades.

\section{Modal analysis for wind turbine blade structure}

A modal analysis for structural dynamics was performed in order to obtain the natural mode shapes and frequencies of the blade structure. After defining the material properties in the software, the sectional blade properties were automatically computed and a modal analysis was performed. The modal analysis of a horizontal axis wind turbine blade was carried out at $5 \mathrm{~m} / \mathrm{min}$ rotating speeds. Table 5 shows the results of all considered mode types, i.e. flap wise, edge wise, torsional and longitudinal. Four mode shapes were considered for each selected mode type and the selected natural fiber reinforced composite.

As can be observed from Table 5, the result obtained for flap wise, edgewise, torsional and longitudinal Eigen frequency of the turbine blade varies with the type of composite materials used. Thus, material variation affects the vibration mode of the blade. During the design of a wind turbine blade, the $1^{\text {st }}$ flap-wise, $2^{\text {nd }}$ flapwise, $1^{\text {st }}$ edge-wise and the $1^{\text {st }}$ torsional natural frequencies were determined as a minimum [20]. It was noted that only the frequency range between $0.5 \mathrm{~Hz}$ and $30 \mathrm{~Hz}$ [21] is of relevance to the considered wind turbine blades. This study (Table 5) shows that for the blade studied, only the flapwise and edge wise modes need to be considered.

Figure 5 and 6 show plots of the Eigen values as function of the four mode shape type. The plots are intended to make comparison of the flap wise, edge wise, torsional and longitudinal modes of vibration for each of the selected natural fibers. While banana/epoxy and abaca/ epoxy give low value of Eigen frequency for all cases, ramie/epoxy and curanua/epoxy give a high Eigen frequency. Generally, compared with the E-glass/epoxy fiber composites, many of the selected natural fiber/epoxy composites perform equivalent to the E-glass/epoxy composites. It was also observed that the material that have high stiffness value are characterized by a high Eigen value and vice-versa. 
Table 4. Results of equivalent stress, total deformation and blade weight

\begin{tabular}{|l|c|c|c|c|}
\hline \multicolumn{1}{|c|}{ Material } & $\begin{array}{c}\text { Equivalent (von-Mises) } \\
\text { stress }(\mathrm{MPa})\end{array}$ & $\begin{array}{c}\text { Deformation in } x \\
\text { direction }(\mathrm{m})\end{array}$ & $\begin{array}{c}\text { Deformation in } z \\
\text { direction }(\mathrm{m})\end{array}$ & $\begin{array}{c}\text { Weight of the blade } \\
(\mathrm{kg})\end{array}$ \\
\hline Banana/epoxy & 405.77 & 0.758 & 0.894 & 38.83 \\
\hline Abaca/epoxy & 406.1 & 0.705 & 0.834 & 38.83 \\
\hline Flax/epoxy & 431.42 & 0.303 & 0.345 & 38.83 \\
\hline Sisal/epoxy & 421.41 & 0.488 & 0.564 & 38.05 \\
\hline Pineapple/epoxy & 431.75 & 0.292 & 0.332 & 39.303 \\
\hline Kenaf/epoxy & 426.92 & 0.398 & 0.456 & 37.27 \\
\hline Hemp/epoxy & 429.94 & 0.332 & 0.379 & 38.52 \\
\hline Bamboo/epoxy & 421.58 & 0.546 & 0.630 & 33.83 \\
\hline Jute/epoxy & 431.38 & 0.309 & 0.352 & 38.2 \\
\hline Curaua /epoxy & 434.06 & 0.267 & 0.304 & 37.27 \\
\hline Ramie/epoxy & 436.33 & 0.216 & 0.2457 & 38.83 \\
\hline E-glass/epoxy & 422.53 & 0.325 & 0.375 & 54.48 \\
\hline
\end{tabular}

Table 5. Result of mode shape for different mode types

\begin{tabular}{|c|c|c|c|c|c|}
\hline \multirow{2}{*}{ Mode type } & \multirow{2}{*}{ Mode No. } & \multicolumn{4}{|c|}{ Shape parameter (Natural frequency $\mathrm{Hz}$ ) } \\
\hline & & Bamboo/epoxy & Pineapple/epoxy & Abaca/epoxy & Glass/epoxy \\
\hline \multirow{4}{*}{ Flap wise } & 1 & 3.37 & 4.28 & 2.757 & 3.44 \\
\hline & 2 & 12.22 & 15.65 & 9.88 & 12.48 \\
\hline & 3 & 23.53 & 30.2 & 18.97 & 24 \\
\hline & 4 & 41.57 & 53.37 & 33.478 & 42.47 \\
\hline \multirow{4}{*}{ Edge wise } & 1 & 8.69 & 11.16 & 7.00 & 8.88 \\
\hline & 2 & 34.37 & 44.18 & 27.65 & 35.12 \\
\hline & 3 & 96.59 & 124.18 & 77.64 & 98.7 \\
\hline & 4 & 190.608 & 245 & 153.9 & 194.77 \\
\hline \multirow{4}{*}{ Torsional } & 1 & 263.49 & 338.82 & 211.756 & 269.255 \\
\hline & 2 & 524.95 & 675.05 & 421.88 & 536.44 \\
\hline & 3 & 811.85 & 1043.98 & 652.455 & 829.62 \\
\hline & 4 & 1014.22 & 1432.79 & 895.453 & 1138.6 \\
\hline \multirow{4}{*}{ Longitudinal } & 1 & 241.92 & 311.1 & 194.425 & 247.2 \\
\hline & 2 & 448.11 & 576.235 & 360.13 & 457.9 \\
\hline & 3 & 836.488 & 1075.65 & 672.25 & 854.7 \\
\hline & 4 & 1288.58 & 1657 & 1035.58 & 1316.7 \\
\hline
\end{tabular}

\section{CONCLUSION}

In this paper, the performance of the selected natural fiber composites was investigated when used for wind turbine blade application. The mechanical properties such as elastic modulus and density of the constituent materials were taken from published papers and the mechanical properties of the composites were estimated by using a modified Halphin-Tsai semi-empirical model. The Qblade software, which is a BEM based finite element analysis tool for wind turbine blade, was used to model and simulate the blade performance. The stress distribution, deformation and weight of different natural fiber reinforced with epoxy for the selected blade profile, under dynamic loads, were analyzed and the natural frequency of each material along the flap wise, edge wise, torsional and longitudinal was numerically computed by QFEM and discussed. On the basis of the conducted analysis, the following conclusions can be mentioned:

- The replacement of glass/epoxy composite based wind turbine blades by natural fiber reinforced composites leads to a weight reduction per blade by $27.9 \%$ to $38 \%$.

- In terms of stress, the deformation level and natural frequencies some of the natural fiber reinforced composites such as Ramie, Curaua and pineapple have an almost identical performance to glass/epoxy.

- The additional benefit is, however, the natural fibers are renewable, recyclable and inexpensiv 


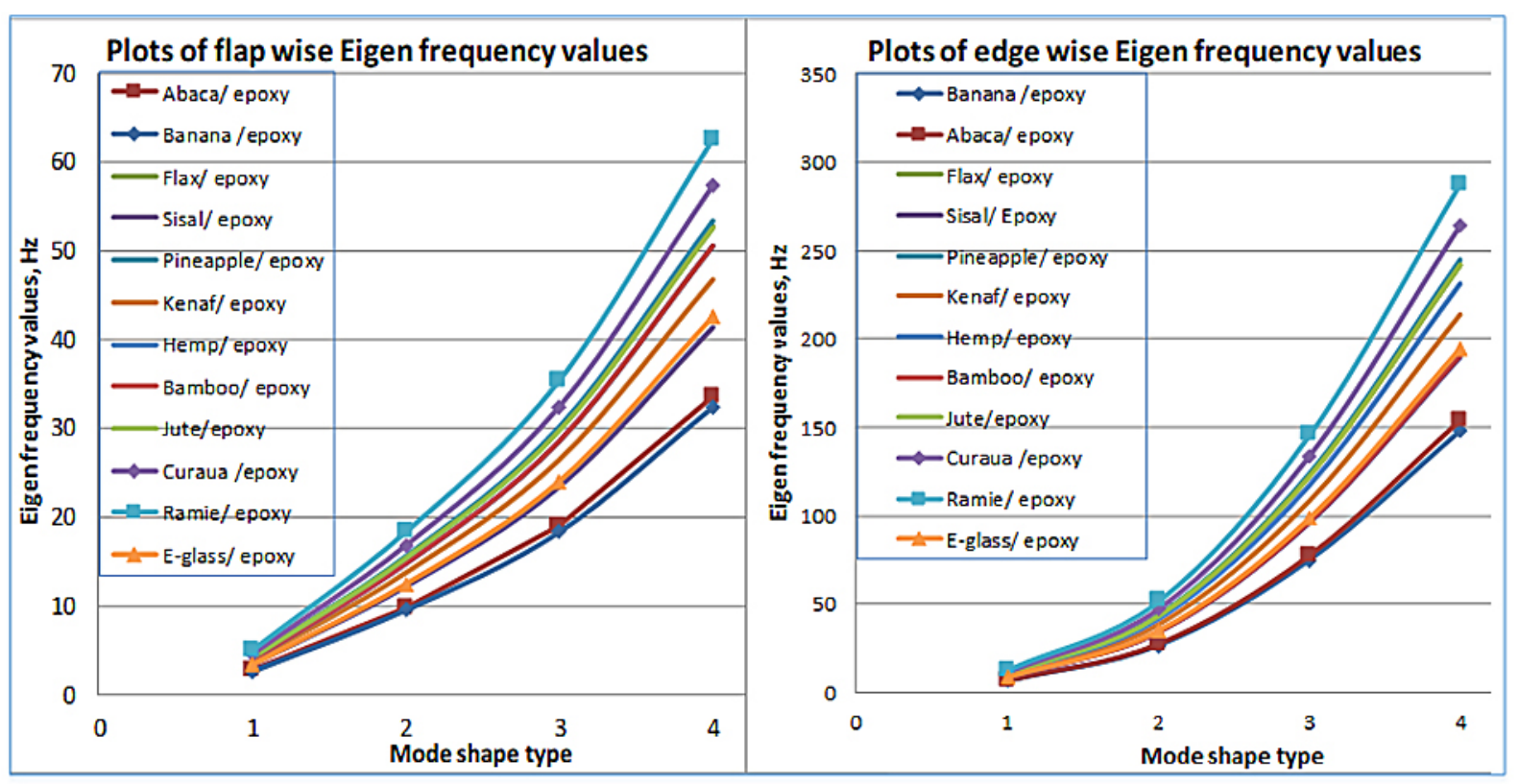

Fig. 5 Comparison of the Eigen frequencies of the natural fiber reinforced composites for the flap wise and edge wise modes

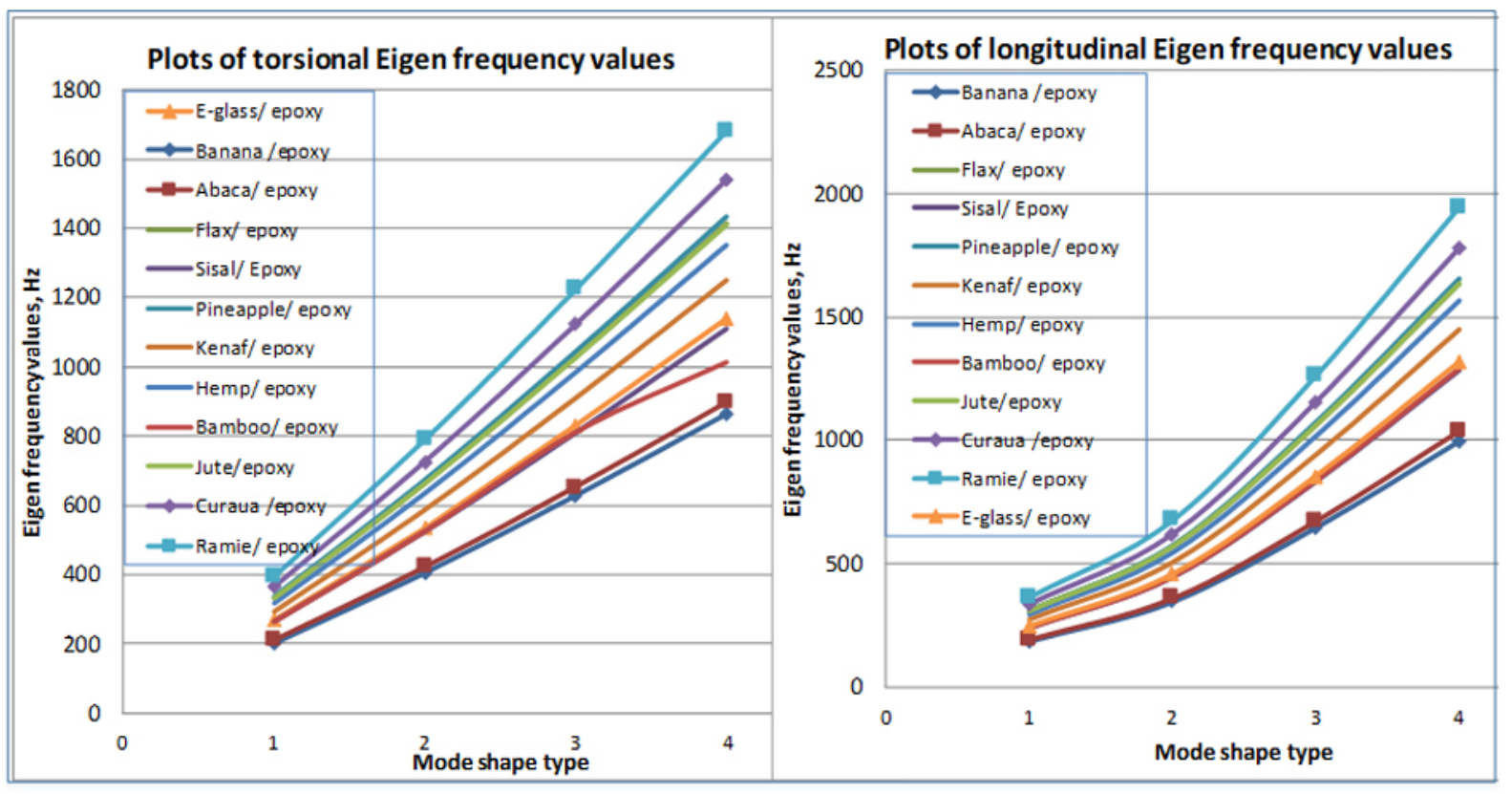

Fig. 6 Comparison of the Eigen frequencies of the natural fiber reinforced composites for the torsional and longitudinal modes

\section{REFERENCES}

1. Baoqing X. and De T. 2012. Simulation and test of the blade models' output characteristics of wind turbine, Energy Procedia, 17, 1201-1208.

2. Hansen M.O.L., Sørensen J.N., Voutsinas S., Sørensen N. and Madsen H.A. 2006. State of the art in wind turbine aerodynamics and aeroelasticity, Prog. Aerosp. Sci. 42, 285-330.

3. Kong C., Bang J. and Sugiyama Y. 2005. Structural investigation of composite wind turbine blade considering various load cases and fatigue life, Energy, $30,2101-2114$.

4. Auger D., Wang Q., Trevelyan J., Huang S. and Zhao W. 2018. Investigating the quality inspection process of offshore wind turbine blades using Bspline surfaces, Meas. 115, 162-172.

5. Raon P.D., Rao D.V, Naidu A.L. and Bahubalendruni M.V.A.R. 2015. Mechanical Properties of Banana fiber Reinforced Composites and Manu- 
facturing Techniques: A Review, Int. J. Res. Dev Technol. 8(5), 2349 - 3585.

6. Kalagi G., Patil R. and Nayak N. 2016. Natural fiber reinforced polymer composite materials for wind turbine blade applications, Int. J. Scie. Dev. Res. 1(9), 2455-2631.

7. Deshmukh A.V. and Shekhawat S.P. 2017. Analysis on wind turbine blade using composite materials, Int. J. Innov. Res. Sci. Eng. Technol. 6(1), 412-418.

8. Yeh M.K., Cheng Y.C. and Wang C.H. 2015. Finite element stress analysis of wind blade structure under wind pressure. Taiwan Wind Energy Conference, Taipei, Taiwan, Paper No. SI_07 (in Chinese)

9. Tartibu L.K., Kilfoil M. and Merwe A.J. van Der 2012. Vibration analysis of a variable length blade wind turbine, Int. J. Adv. Eng. Technol. 4(1), 630-639.

10. Osoka E.C. and Onukwuli O.D. 2018. A modified Halpin-Tsai model for estimating the modulus of natural fiber reinforced composites, Int. J. Eng. Sci. Invent. 7(5), 63-70.

11. Akil H.M., Omar M.F., Mazuki A.A.M., Safiee S., Ishak Z.A.M. and Abu Bakar A. 2011. Kenaf fiber reinforced composites: A review, Mater. Des. 32, 4107-4121.

12. Brouwer W.D.R. 2001. Natural fibre composites in structural components: Alternative applications for sisal? Technical report no. 14, The Ntherlands.
13. Fidelis, M.E.A., Pereira, T.V.C., Gomes O. da F.M., Silva de A. and Filho, R.D.T. 2013. The effect of fiber morphology on the tensile strength of natural fibers, J. Mater. Res. Technol. 2, 149-157.

14. Kaw A. 2006. Mechanics of composite materials, 2nd ed. Taylor \& Francis Group, NY, USA.

15. Alene A. 2013. Design and analysis of bamboo and E-glass fiber reinforced epoxy hybrid composite for wind turbine blade shell, Master Thesis, Addis Ababa University, Ethiopia.

16. ICE 61400-1, International Standard: Wind Turbines - Part 1: Design requirements, 2005.

17. Qblade website: http://www.q-blade.org/: Last visited, 2019-09-20.

18. Marten J.W., Pechlivanoglou G., Nayeri C.N. and Paschereit C.O. 2013. Qblade: An open source tool for design and simulation of horizontal and vertical axis wind turbines, Int. J. Emerging Technol. Adv. Eng. 3(3), 264-269.

19. Corke T. and Nelson R. 2018. Wind energy design, 1st ed. CRC Press, NY, USA.

20. Eker B., Akdogan A. and Vardar A. 2006. Using of composite materials in wind turbine blades, J. Appl. Sci. 6(14) 2917-2921.

21. Larsen G.C., Hansen M.H., Baumgart A. and Carlen I. 2002. Modal analysis of wind turbine blades. Technical Report, Risø-R-1181. Risø National Laboratory, Denmark. 